\title{
Genetic Differences and Environmental Variations in Carotenoid Contents of Fruit Flesh in Parental Population Used in Citrus Breeding in Japan
}

\author{
Keisuke Nonaka ${ }^{1}$ \\ Citrus Research Division, National Agriculture and Food Research Organization Institute \\ of Fruit Tree Science (NIFTS), Minamishimabara, Nagasaki, 859-2501, Japan \\ Masayuki Kita and Yoshinori Ikoma \\ Citrus Research Division, NIFTS, Shimizu, Shizuoka, 424-0292, Japan \\ Hiroshi Fukamachi and Atsushi Imai \\ Citrus Research Division, NIFTS, Minamishimabara, Nagasaki, 859-2501, Japan \\ Terutaka Yoshioka \\ Citrus Research Division, NIFTS, Shimizu, Shizuoka, 424-0292, Japan \\ Masahiko Yamada \\ Breeding and Pest Management Division, NIFTS, Tsukuba, Ibaraki, 305-8605, Japan \\ AdDitional INDEX words. breeding strategy, broad-sense heritability, $\beta$-cryptoxanthin, mandarin, location effect
}

\begin{abstract}
To aid the breeding of citrus (Citrus sp.) for high carotenoid content, we assayed the fruit flesh of 48 cultivars and selections within a parental population consisting of both old and new cultivars and selections at two locations in Japan. The mean total carotenoid (CAR) content across all 48 cultivars and selections over the two locations was $26.59 \mu \mathrm{g} \cdot \mathrm{g}^{-1}$ fresh weight $(\mathrm{FW})$. The most prominent carotenoid was $\beta$-cryptoxanthin [BCR (12.09 $\left.\mu \mathrm{g} \cdot \mathrm{g}^{-1} \mathrm{FW}\right)$ ] followed by violaxanthin [VIO $\left.\left(8.04 \mu \mathrm{g} \cdot \mathrm{g}^{-1} \mathrm{FW}\right)\right], \zeta$-carotene $\left(2.27 \mu \mathrm{g} \cdot \mathrm{g}^{-1} \mathrm{FW}\right)$, phytoene $\left(1.86 \mu \mathrm{g} \cdot \mathrm{g}^{-1}\right.$ FW), and $\beta$-carotene $\left(0.96 \mu \mathrm{g} \cdot \mathrm{g}^{-1} \mathrm{FW}\right)$. Broad-sense heritabilities of CAR, BCR, and VIO were 0.80 or greater based on a sample of five fruit on one tree per location in one time sampling for 1 year in a location, which were revealed to be large enough for gauging the genetic variation. The mean CAR and BCR contents in a cultivar and selection group in advanced generations were nearly the same as in the initial population, suggesting no or little selection pressure on carotenoid content in the citrus breeding so far. High carotenoid contents in cultivars and selections released or selected recently, which have high fruit qualities, suggest their high potential for combining high fruit quality and high carotenoid content in breeding. We showed that the critical phenotypic value used in selecting hybrid seedlings can be determined from the estimate of environmental variance.
\end{abstract}

Carotenoid pigments are essential for protecting plants from photo-oxidative damage and photoinhibition in photosynthesis (Goodwin, 1980). They are also essential to human health: a number of carotenoids serve as provitamin $\mathrm{A}$, which is essential in the human diet, and as antioxidants, which reduce the risk of various chronic diseases (Olson, 1989). In particular, $\beta$-cryptoxanthin has various functions in human health, including the prevention of various cancers, diabetes, and osteoporosis (Nishino et al., 2000; Sugiura et al., 2002a, 2002b, 2004, 2006, 2008, 2011; Tanaka et al., 2000; Yamaguchi, 2008). The risk for diabetes decreased as the serum BCR concentration increased in people who ate at least four Satsuma mandarin (Citrus unshiu) fruit per day (Sugiura et al., 2002a, 2002b).

The contents and composition of carotenoids in citrus fruit vary greatly depending on cultivar and growing conditions (Dhuique-Mayer et al., 2005, 2009; Fanciullino et al., 2006; Goodner et al., 2001; Gross, 1987; Ikoma et al., 2001; Kato

Received for publication 2 May 2012. Accepted for publication 22 June 2012. We thank Akihiko Sato of NIFTS and Takeshi Kuniga of National Agriculture and Food Research Organization Agricultural Research Center for Western Region for critical review of the manuscript.

${ }^{1}$ Corresponding author. E-mail: nonakak6@affrc.go.jp. et al., 2004; Matsumoto et al., 2007). The carotenoid composition in 25 citrus cultivars, which was dominated by violaxanthin and BCR, agreed with the cultivar classification based on molecular markers (Fanciullino et al., 2006; Nicolosi et al., 2000). Matsumoto et al. (2007) investigated the seasonal patterns of carotenoid accumulation in both flavedo and juice sacs of 39 citrus cultivars, including a wide range of species in Tanaka's (1954) classification and classified the cultivars into four clusters by the carotenoid profile in juice sacs, mainly VIO, BCR, and phytoene (PHY). Previous reports of carotenoid composition focus mainly on the initial citrus species and their mutations, and not so much on hybrid cultivars produced by breeding (Dhuique-Mayer et al., 2005, 2009; Fanciullino et al., 2006; Goodner et al., 2001; Matsumoto et al., 2007). Goodner et al. (2001) showed that the peak area of BCR determined by high-performance liquid chromatography in mandarin cultivars is larger than that in sweet orange (Citrus sinensis) cultivars and that the BCR contents in juice characterized the grouping of mandarin, sweet orange, and their hybrids, but they did not quantify the carotenoid content in each group.

The citrus industry in Japan is led by Satsuma mandarin, which is of Japanese origin and is well adapted to the climate in 
Japan. Satsuma mandarin is highly productive, it is disease- and cold-tolerant, and its fruit is seedless and easy to peel, but the fruit is small and its sugar content is moderate. To increase the market demand for citrus fruit, we need to develop new mandarin-type cultivars with a high sugar content, large fruit ( $\approx 200 \mathrm{~g}$ ), and excellent flavor.

A citrus cross-breeding program was begun in 1937 at the then National Horticulture Research Station of the Ministry of Agriculture and Forestry [now Okitsu Citrus Research Station of the National Agriculture and Food Research Organization Institute of Fruit Tree Science (NIFTS)] and has continued since at the NIFTS Okitsu and Kuchinotsu Citrus Research Stations. Breeding is focused mainly on improving fruit quality, defined as high sugar content, excellent flavor, seedlessness, ease of peeling, and a thin locular membrane, which are characteristic of mandarin. The breeding program has released 51 new cultivars of citrus since 1963. It has produced advanced generations by crossing mainly mandarins and their descendants, adding newly released cultivars and new selections to the total potential parental population (Table 1). Recently, a high carotenoid content, especially total CAR and BCR contents, has been added to the breeding targets because of carotenoids' various health benefits. However, carotenoid content has not been evaluated in the parental population.

Carotenoid content is a quantitative trait that depends on environmental conditions such as location, year, tree, and fruit, and therefore its broad-sense heritability and environmental variances have to be estimated for efficient breeding (Nyquist, 1991; Yamada et al., 1993, 1994). Accordingly, the aims of this study were 1) to evaluate the genetic differences underlying the carotenoid content of fruit flesh in the NIFTS parental population; 2) to estimate the broad-sense heritabilities of and environmental variations in carotenoid contents at the NIFTS Kuchinotsu and Okitsu Citrus Research Stations; and 3) to suggest a breeding strategy to increase the content of carotenoids, especially BCR.

\section{Materials and Methods}

Plant materials. Forty-eight citrus cultivars and selections that have been repeatedly used as parents in the NIFTS citrus breeding program were chosen (Table 1). Five fruit were sampled from one tree of each cultivar and selection (genotype) at both Kuchinotsu Citrus Research Station in Nagasaki, Japan (lat. $32^{\circ} 59^{\prime} \mathrm{N}$, long. $130^{\circ} 18^{\prime} \mathrm{E}$ ) and Okitsu Citrus Research Station in Shizuoka, Japan (lat. $35^{\circ} 05^{\prime} \mathrm{N}$, long. $138^{\circ} 52^{\prime} \mathrm{E}$ ) in late Dec. 2008. The flesh was separated from the fruit, immediately frozen in liquid nitrogen, and kept at $-30{ }^{\circ} \mathrm{C}$ until analysis. The five fruit were bulked for analysis.

Carotenoid extraction and SAPOnification. Carotenoids were extracted and analyzed according to the method of Kato et al. (2004). Sample was homogenized in $40 \%(\mathrm{v} / \mathrm{v})$ methanol $(\mathrm{MeOH})$ containing $10 \%(\mathrm{w} / \mathrm{v})$ magnesium carbonate basic. Pigments were extracted from the residue in a diethyl ether: $\mathrm{MeOH}(7: 3, \mathrm{v} / \mathrm{v})$ solution containing $0.1 \%(\mathrm{w} / \mathrm{v})$ 2,6-di-tertbutyl-4-methylphenol and partitioned into diethyl ether. The diethyl ether phase was washed two times with NaCl-saturated water and saponified with $20 \%$ (w/v) methanolic $\mathrm{KOH}$ for $18 \mathrm{~h}$ in the dark in a nitrogen atmosphere at room temperature. The water-soluble extract was then removed by the addition of $\mathrm{NaCl}$-saturated water. Pigments repartitioned into the diethyl ether phase were recovered and dried by evaporation. The residue was redissolved in $5 \mathrm{~mL}$ of a methyl tert-butyl ether (MTBE):MeOH $(1: 1, \mathrm{v} / \mathrm{v})$ solution.

Carotenoid determination. Carotenoids in $20 \mu \mathrm{L}$ were separated by reverse-phase high-performance liquid chromatography (LC-2000Plus; Jasco, Tokyo, Japan) fitted with a YMC Carotenoid S-5 column $(250 \times 4.6 \mathrm{~mm}$ i.d.; Waters, Milford, MA) at a flow rate of $1 \mathrm{~mL} \cdot \mathrm{min}^{-1}$. The eluent was monitored by a photodiode array detector (MD-910; Jasco). Each sample was analyzed by three different gradient elution schedules: 1) to assay all-trans-violaxanthin (t-VIO), 9-cisviolaxanthin ( $c$-VIO), lutein (LUT), BCR, $\alpha$-carotene (ACA), and PHY, the eluent composition (all ratios expressed as $\mathrm{v} / \mathrm{v}$ ) altered from an initial 95\% $\mathrm{MeOH}, 1 \% \mathrm{MTBE}$, and 4\% water for $30 \mathrm{~min}$ through a linear gradient to $6 \% \mathrm{MeOH}, 90 \% \mathrm{MTBE}$, and $4 \%$ water over $60 \mathrm{~min} ; 2$ ) to assay $\zeta$-carotene (ZCA) and $\beta$-carotene (BCA), the composition altered from an initial $50 \%$ $\mathrm{MeOH}, 46 \% \mathrm{MTBE}$, and 4\% water through a linear gradient to $6 \% \mathrm{MeOH}, 90 \% \mathrm{MTBE}$, and $4 \%$ water over $60 \mathrm{~min}$; and 3) zeaxanthin (ZEA) was assayed by the gradient elution schedule of Rouseff et al. (1996): the composition altered from 90\% $\mathrm{MeOH}, 5 \% \mathrm{MTBE}$, and 5\% water through a linear gradient to $95 \% \mathrm{MeOH}$ and $5 \% \mathrm{MTBE}$ over $12 \mathrm{~min}$, then to $86 \% \mathrm{MeOH}$ and $14 \% \mathrm{MTBE}$ over $8 \mathrm{~min}, 75 \% \mathrm{MeOH}$, and 25\% MTBE over $10 \mathrm{~min}$ and $50 \% \mathrm{MeOH}$ and $50 \% \mathrm{MTBE}$ over $20 \mathrm{~min}$.

The peaks were identified by comparison of their specific retention times and absorption spectra with those of authentic standards. The concentrations of the standard solutions were estimated on the basis of the absorption coefficient at $286 \mathrm{~nm}$ for PHY; $400 \mathrm{~nm}$ for ZCA; $452 \mathrm{~nm}$ for $t$-VIO, $c$-VIO, LUT, BCR, ACA, and ZEA; and $453 \mathrm{~nm}$ for BCA (Davies, 1976). The sample concentrations were estimated from standard curves. VIO and ZCA were obtained as the sums of isomers, and total CARs as the sum of the eight carotenoids.

Statistical analysis. Because the mean carotenoid contents were positively correlated with the SD, data were logtransformed before statistical analysis. The correlations were not significant after transformation.

The carotenoid content in the five fruit from each tree contained both genetic and environmental components, described thus:

$$
P_{i j}=\mu_{i}+g_{j}+e_{i j}(i=1,2 ; j=1,2, \ldots, 48)
$$

where $P_{i j}$ is the carotenoid content (phenotypic value) of the $j$ th genotype at the $i$ th location, $\mu_{i}$ is a constant specific to the $i$ th location, $g_{j}$ is a random effect contributed by the $j$ th genotype, and $e_{i j}$ is a random effect contributed by the $j$ th genotype at the $i$ th location.

As the sample of a genotype at a location consisted of five fruit from one tree, $e_{i j}$ contains the effects of within-tree sampling variation, a random effect resulting from tree within genotype, yearly effect, and the interactions among genotype, tree, year, and location. Here, we defined the effect of genotype as the common genotypic effect over the two locations, which do not include the interaction between genotype and location. Because $\mu_{1}$ and $\mu_{2}$ were constants specific to Kuchinotsu and Okitsu, respectively, the location effect was defined as $\mu_{1}-\mu_{2}$. Values of $g_{j}, e_{1 j}$, and $e_{2 j}$ were assumed to be independent and to be normally distributed with a mean of zero and variance of $\sigma_{g}{ }^{2}$, $\sigma_{e 1}^{2}$, and $\sigma_{e 2}^{2}$, respectively $\left(\sigma_{e 1}^{2} \neq \sigma_{e 2}^{2}\right)$.

When the variance of the phenotype $P_{i j}$ is denoted as $\sigma_{P i}{ }^{2}$, $\sigma_{P i}{ }^{2}=\sigma_{g}{ }^{2}+\sigma_{e i}{ }^{2}$, broad-sense heritability at the $j$ th location was defined as $h_{\mathrm{B} j}{ }^{2}=\sigma_{g}{ }^{2} /\left(\sigma_{g}{ }^{2}+\sigma_{e j}{ }^{2}\right)$. 
Table 1. Citrus cultivars and selections used for carotenoids analysis in fruit flesh and their species or parentage. ${ }^{z}$

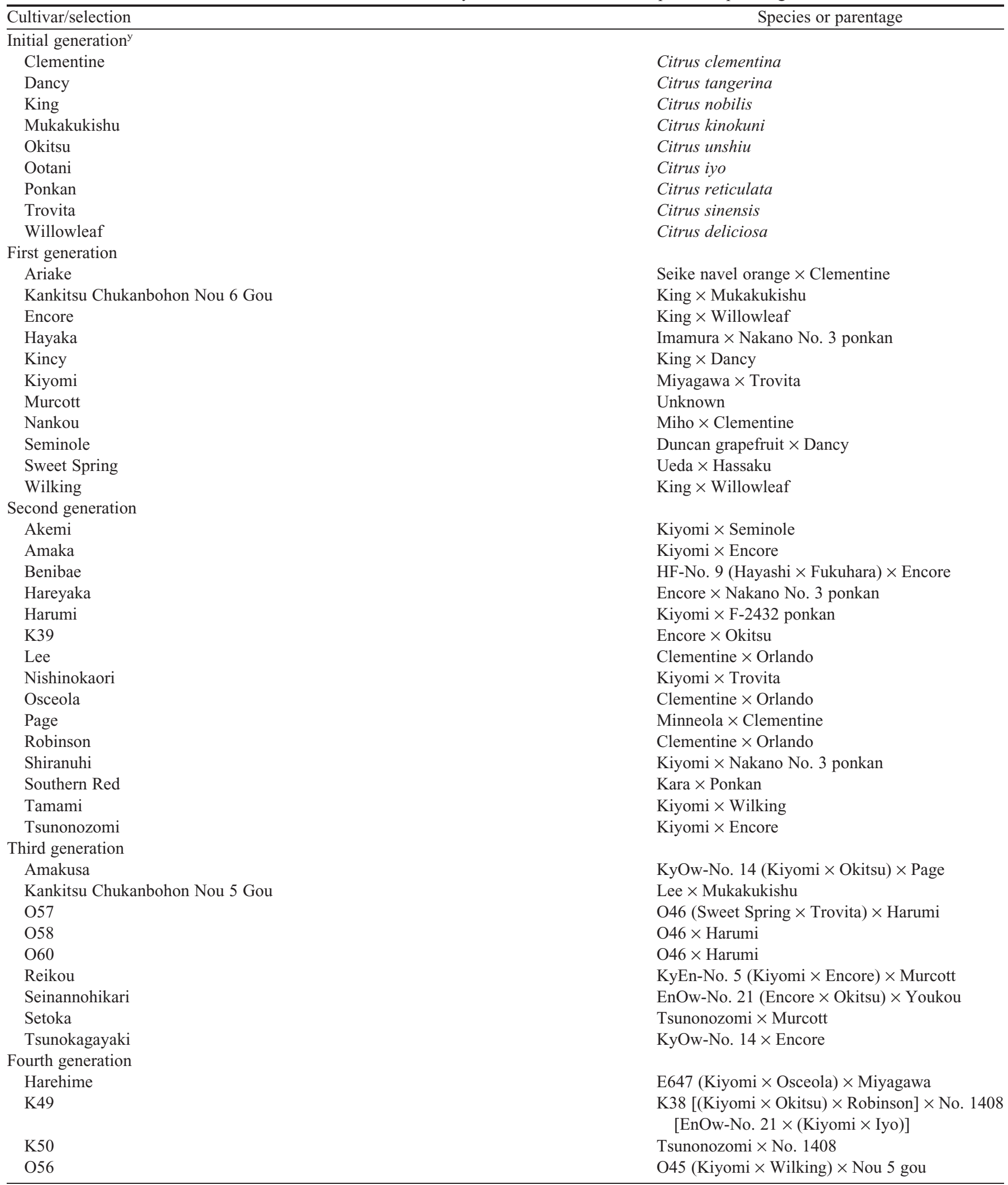

${ }^{\mathrm{z}}$ Citrus species are referred to Tanaka's system (Tanaka, 1954).

${ }^{\mathrm{y}}$ Initial generation consist of original cultivars of citrus. First generation consist of hybrids between cultivars in initial generation. Second generation consists of hybrids between a cultivar in first generation and another in the first or initial generation. Third (fourth) generation consists of hybrids between a cultivar or selection in the second (third) generation and another in the second (third) or earlier generation. 
When the covariance of $P_{1 j}$ and $P_{2 j}$ is denoted as $\operatorname{Cov}\left(P_{1 j}, P_{2 j}\right)$ :

$$
\begin{aligned}
\operatorname{Cov}\left(P_{1 j}, P_{2 j}\right)= & \sum_{j}\left(P_{1 j}-\bar{P}_{1}\right)\left(P_{2 j}-\bar{P}_{2}\right) /(n-1) \\
= & \sum_{j}\left[\mu_{1}+g_{j}+e_{1 j}-\left(\mu_{1}+\bar{g}_{j}+\bar{e}_{1 j}\right)\right] \\
& \times\left[\mu_{2}+g_{j}+e_{2 j}-\left(\mu_{2}+\bar{g}_{j}+\bar{e}_{2 j}\right)\right] /(n-1) \\
= & \sum_{j}\left(g_{j}-\bar{g}_{j}\right)^{2} /(n-1) \\
& +\sum_{j}\left(g_{j}-\bar{g}_{j}\right)\left(e_{1 j}-\bar{e}_{1}\right) /(n-1) \\
& +\sum_{j}\left(g_{j}-\bar{g}_{j}\right)\left(e_{2 j}-\bar{e}_{2}\right) /(n-1) \\
& +\sum_{j}\left(e_{1 j}-\bar{e}_{1}\right)\left(e_{2 j}-\bar{e}_{2}\right) /(n-1)
\end{aligned}
$$

where $n$ is the number of genotypes (48). Because $g_{j}, e_{1 j}$, and $e_{2 j}$ were independent, the second and subsequent terms were expected to be zero; i.e., $\operatorname{Cov}\left(P_{1 j}, P_{2 j}\right)$ was expected to be:

$$
\sum_{j}\left(g_{j}-\bar{g}\right)^{2} /(n-1)=\sigma_{g}^{2} .
$$
$\left(b_{1}\right)$ is:

In the regression of $P_{1 j}$ against $P_{2 j}$, the regression coefficient

$$
b_{1}=\operatorname{Cov}\left(P_{1 j}, P_{2 j}\right) / \sigma_{P 1}^{2}=\sigma_{g}^{2} /\left(\sigma_{g}^{2}+\sigma_{e 1}^{2}\right)=h_{B 1}^{2} .
$$

Therefore, the regression coefficient $b_{1}$ is the broad-sense heritability at location 1 . Genetic variance $\left(\sigma_{g}^{2}\right)$ was calculated as $b_{1} \times \sigma_{P 1}^{2}$, and environmental variance $\left(\sigma_{e 1}^{2}\right)$ was calculated as $\sigma_{P 1}{ }^{2}-\sigma_{g}{ }^{2}$. In the same way, $b_{2}$ and $\sigma_{e 2}{ }^{2}$ at location 2 were calculated.

ACA and LUT were not major carotenoid components in any genotypes and were not detected in many, so we did not analyze ACA and LUT statistically.
'Okitsu' (27.39 $\left.\mu \mathrm{g} \cdot \mathrm{g}^{-1}\right)$, a leading Satsuma mandarin cultivar in Japan known for its high carotenoid content (Fanciullino et al., 2006; Kato et al., 2004; Matsumoto et al., 2007). BCR had the highest content among the eight carotenoids in 39 of the 48 genotypes, including 'Kiyomi', 'Tamami', and 'Okitsu'. VIO had the highest content in nine genotypes, including 'Trovita', 'Wilking', and 'King'.

The highest BCR contents were found in 'Seinannohikari' (29.07 $\left.\mu \mathrm{g} \cdot \mathrm{g}^{-1}\right)$, 'Tsunokagayaki' (26.01 $\left.\mu \mathrm{g} \cdot \mathrm{g}^{-1}\right)$, and 'Encore' (21.41 $\left.\mu \mathrm{g} \cdot \mathrm{g}^{-1}\right)$ (Fig. 1). These cultivars are descendants of 'King'. However, 'King' had a low BCR content but a high VIO content. The BCR content of 'Seinannohikari' was $\approx 50 \%$ more than that of the popular 'Okitsu' $\left(19.45 \mu \mathrm{g} \cdot \mathrm{g}^{-1}\right)$.

'King' had the highest mean VIO content $\left(43.98 \mu \mathrm{g} \cdot \mathrm{g}^{-1}\right)$, approximately double those of the next highest, 'Encore' (23.76 $\left.\mu \mathrm{g} \cdot \mathrm{g}^{-1}\right)$ and 'Kankitsu Chukanbohon Nou 6 Gou' (20.75 $\left.\mu \mathrm{g} \cdot \mathrm{g}^{-1}\right)$. O57 had the highest mean ZCA content $\left(10.22 \mu \mathrm{g} \cdot \mathrm{g}^{-1}\right)$ followed by 'Seinannohikari' $\left(6.18 \mu \mathrm{g} \cdot \mathrm{g}^{-1}\right)$, 'Osceola' (4.46 $\mu \mathrm{g} \cdot \mathrm{g}^{-1}$ ), and 'Robinson' (4.02 $\left.\mu \mathrm{g} \cdot \mathrm{g}^{-1}\right)$. O57 had the highest mean PHY content $\left(5.75 \mu \mathrm{g} \cdot \mathrm{g}^{-1}\right)$ followed by 'Robinson' (5.05 $\left.\mu \mathrm{g} \cdot \mathrm{g}^{-1}\right)$, 'Osceola' (4.56 $\left.\mu \mathrm{g} \cdot \mathrm{g}^{-1}\right)$, and 'Seinannohikari' $\left(4.53 \mu \mathrm{g} \cdot \mathrm{g}^{-1}\right)$. The highest BCA contents were found in 'Seinannohikari' (4.08 $\left.\mu \mathrm{g} \cdot \mathrm{g}^{-1}\right)$, 'Osceola' $\left(2.74 \mu \mathrm{g} \cdot \mathrm{g}^{-1}\right)$, and 'Benibae' $\left(2.22 \mu \mathrm{g} \cdot \mathrm{g}^{-1}\right)$. The highest ZEA contents were found in 'Kankitsu Chukanbohon Nou 6 Gou' $\left(1.85 \mu \mathrm{g} \cdot \mathrm{g}^{-1}\right)$, 'King' $\left(1.63 \mu \mathrm{g} \cdot \mathrm{g}^{-1}\right)$, and 'Tamami' $\left(1.28 \mu \mathrm{g} \cdot \mathrm{g}^{-1}\right)$. LUT contents were below the detection limit in 15 of the 48 genotypes although the LUT contents of 'King' $\left(3.60 \mu \mathrm{g} \cdot \mathrm{g}^{-1}\right)$ and 'Nou 6 Gou' $\left(2.36 \mu \mathrm{g} \cdot \mathrm{g}^{-1}\right)$ were higher than the ZEA contents. ACA contents were below the detection limit in 33 cultivars/ selections, although ACA was detected in 'King' $\left(0.29 \mu \mathrm{g} \cdot \mathrm{g}^{-1}\right)$, 'Kankitsu Chukanbohon Nou 6 Gou' $\left(0.25 \mu \mathrm{g} \cdot \mathrm{g}^{-1}\right)$, and 'Benibae' (0.23 $\left.\mu \mathrm{g} \cdot \mathrm{g}^{-1}\right)$.

Broad-sense heritability $\left(h_{\mathrm{B}}{ }^{2}\right)$ and phenotypic and environmental variance estimates of all carotenoid contents at each location are shown in Table 2. The SE of the measurement data (phenotypic value) based on five fruit on one tree for 1 year in a location was the square root value of the environmental

\section{Results}

The mean CAR content across all 48 genotypes over both locations was $26.59 \mu \mathrm{g} \cdot \mathrm{g}^{-1}$ (all contents are expressed as FW). The most prominent carotenoid was BCR (12.09 $\left.\mu \mathrm{g} \cdot \mathrm{g}^{-1}\right)$

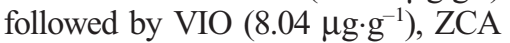
$\left(2.27 \mu \mathrm{g} \cdot \mathrm{g}^{-1}\right)$, PHY $\left(1.86 \mu \mathrm{g} \cdot \mathrm{g}^{-1}\right)$, $\operatorname{BCA}\left(0.96 \mu \mathrm{g} \cdot \mathrm{g}^{-1}\right), \mathrm{ZEA}\left(0.68 \mu \mathrm{g} \cdot \mathrm{g}^{-1}\right)$, LUT $\left(0.63 \mu \mathrm{g} \cdot \mathrm{g}^{-1}\right)$, and ACA $\left(0.04 \mu \mathrm{g} \cdot \mathrm{g}^{-1}\right)$. ZCA in three genotypes, PHY in four, BCA in two, ZEA in one, LUT in 19, and ACA in 37 were not detected, respectively. The means carotenoid contents were calculated as values below the limit of detection and substituted with zero.

The highest mean CAR contents were $64.06 \mu \mathrm{g} \cdot \mathrm{g}^{-1}$ in 'King' and $58.87 \mu \mathrm{g} \cdot \mathrm{g}^{-1}$ in 'Seinannohikari' (Fig. 1), more than double that of

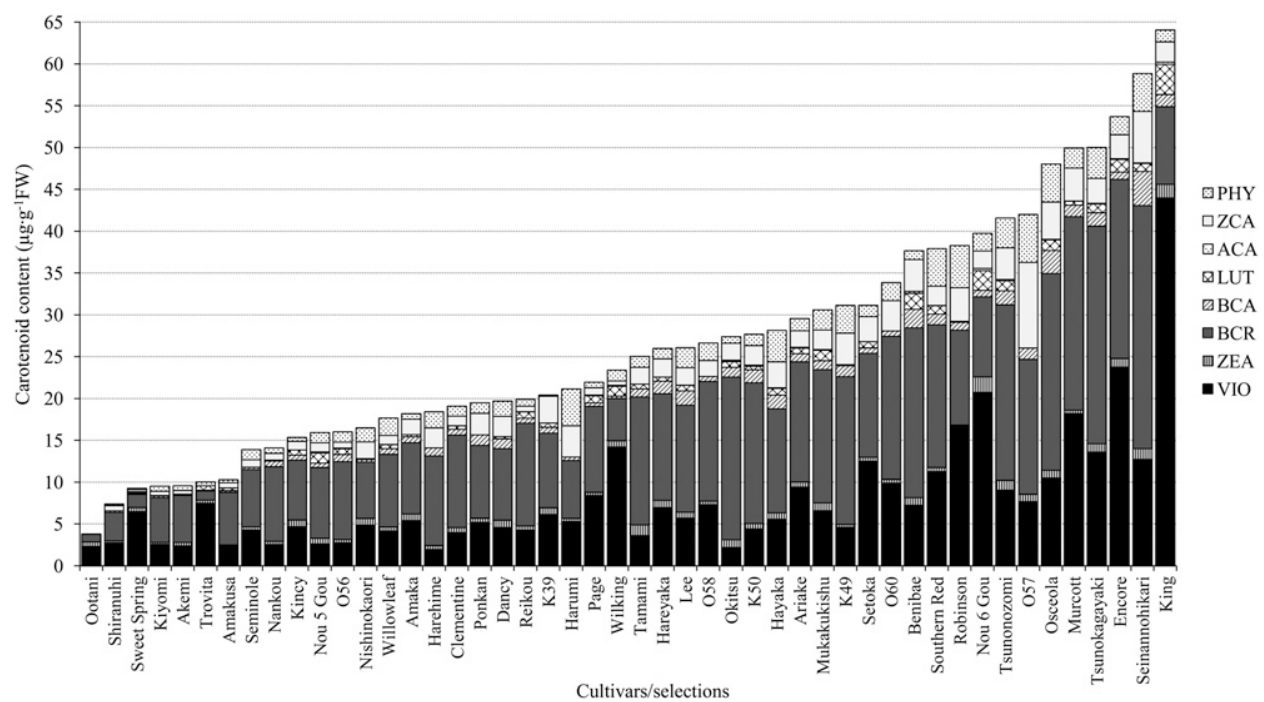

Fig. 1. Genetic differences in carotenoid content in citrus fruit flesh among 48 citrus cultivars and selections: $\mathrm{PHY}=$ phytoene; ZCA $=\zeta$-carotene; $\mathrm{ACA}=\alpha$-carotene; LUT = lutein; $\mathrm{BCA}=\beta$-carotene; $\mathrm{BCR}=$ $\beta$-cryptoxanthin; ZEA = zeaxanthin; VIO = violaxanthin; Kankitsu Chukanbohon Nou 5 Gou = Nou 5 Gou; Kankitsu Chukanbohon Nou 6 Gou = Nou 6 Gou. 
variance estimates $\left(\sigma_{e}^{2}\right)$ divided by the number of samples. The $h_{\mathrm{B}}{ }^{2}$ of CAR was very high, at $0.85 \pm 0.09$ (SE) at Kuchinotsu and $0.80 \pm 0.08$ at Okitsu, respectively. The $h_{\mathrm{B}}{ }^{2}$ values of BCR and VIO were both very high at both locations, at 0.80 or greater \pm 0.1 orless. The $h_{\mathrm{B}}{ }^{2}$ values of ZCA, BCA, and ZEA were slightly lower than those of BCR and VIO with larger SES. Notably, the $h_{\mathrm{B}}{ }^{2}$ of PHY at Okitsu was not high $(0.55 \pm 0.10)$.

The means of all carotenoid contents were higher at Okitsu than at Kuchinotsu (Table 2). The CAR contents at Kuchinotsu $\left(1.281 \log \mu \mathrm{g} \cdot \mathrm{g}^{-1}\right)$ and Okitsu $\left(1.412 \log \mu \mathrm{g} \cdot \mathrm{g}^{-1}\right)$ gave a location effect of 0.131 . The location effects $\left(\mu_{1}-\mu_{2}\right)$ of PHY $(0.217)$ and ZCA (0.215), upstream in the carotenoid biosynthesis pathway (Fig. 2), were higher than those of the downstream BCA (0.125), BCR (0.131), ZEA (0.035), and VIO (0.103).

\section{Discussion}

Broad-sense heritabilities of the contents of most carotenoids in the 48 genotypes were high, indicating that the differences among obtained values for 48 genotypes were mostly genetic. The carotenoid compositions were clearly distinguishable among all 48 genotypes (Fig. 1). The contents of all carotenoids were higher at Okitsu than at Kuchinotsu (Table 2). These differences (i.e., the effect of location) of carotenoid contents were small, which ranged from 0.035 (ZEA) to 0.217 (PHY). The location effect is caused by the environmental difference resulting from climate and cultivated techniques such as pruning, fruit thinning, or watering between at Kuchinotsu and at Okitsu. The high broad-sense heritabilities of carotenoid contents at both locations and the small location effects suggested their minimum environmental effect on genetic differences.
There are no previous reports of broad-sense heritabilities and environmental variances of carotenoid contents in citrus fruit, but there are some reports for other crop species. Haynes et al. (2010) genetically analyzed nine potato (Solanum tuberosum) cultivars for tuber carotenoid content at two sites with similar climatic conditions in 2 years; most broad-sense heritabilities were greater than 0.85 , and although the genotype $\times$ environment interactions were significant, they were much lower than the genotype effect. Farnham and Kopsell (2009) genetically analyzed nine inbred broccoli (Brassica oleracea var. italica) lines for head carotenoid content under three environmental conditions in 3 years; broad-sense heritabilities of lutein and total carotenoids were high, at 0.84 and 0.79 , respectively. These high broad-sense heritabilities are similar to the high heritabilities obtained here, suggesting small environmental fluctuations in carotenoid content in a considerable number of crops. Mandarin cultivars are characterized by high BCR content in the fruit flesh (Dhuique-Mayer et al., 2005, 2009; Fanciullino et al., 2006; Goodner et al., 2001; Matsumoto et al., 2007). Many of the initial genotypes, including Satsuma mandarin, 'Dancy', 'Willowleaf', ponkan (Citrus reticulata), and clementine (Citrus clementina), also have small fruit, loose rind and carpels, limited thorns, and cold tolerance (Hodgson, 1967). The NIFTS parental population consists mainly of advanced generations developed by cross-breeding of initial mandarin genotypes (Table 1). Matsumoto et al. (2007) investigated the carotenoid contents of 39 cultivars from the initial population of citrus defined by Tanaka (1954); the cultivars could be classified into four clusters by the carotenoid profiles in the juice sacs, which were dominated by VIO, BCR, and PHY. One of these clusters, characterized by high PHY and BCR contents and moderate VIO content, consisted mainly of initial mandarin cultivars. The mean carotenoid contents in January in the cluster were high: $5.38 \mu \mathrm{g} \cdot \mathrm{g}^{-1}$ (FW) PHY,

Table 2. Mean carotenoid contents in citrus fruit fresh, their broad-sense heritability, and environmental variance estimates at Kuchinotsu and Okitsu, Japan, in 48 citrus cultivars and selections.

\begin{tabular}{|c|c|c|c|c|c|c|c|c|}
\hline Carotenoid & Location & $\begin{array}{c}\text { Sample } \\
(\text { no. })^{z}\end{array}$ & $\begin{array}{c}\text { Mean carotenoid } \\
\text { content } \\
\left(\mu \mathrm{g} \cdot \mathrm{g}^{-1} \mathrm{FW}\right)\end{array}$ & $\begin{array}{c}\text { Mean log-transformed } \\
\text { value }\left[\log \mu g^{-} \cdot g^{-1}\right. \\
F W( \pm \mathrm{SE})]^{\mathrm{y}}\end{array}$ & $\begin{array}{l}\text { Effect of } \\
\text { location } \\
\left(\mu_{1}-\mu_{2}\right)^{\mathrm{x}}\end{array}$ & $\begin{array}{l}\text { Phenotypic } \\
\text { variance } \\
\left(\sigma_{p}^{2}\right)^{\mathrm{x}}\end{array}$ & $\begin{array}{c}\text { Environmental } \\
\text { variance } \\
\left(\sigma_{e}^{2}\right)^{\mathrm{x}} \\
\end{array}$ & $\begin{array}{c}\text { Broad-sense } \\
\text { heritability } \\
( \pm \mathrm{SE})^{\mathrm{w}} \\
\end{array}$ \\
\hline Phytoene & Kuchinotsu & 44 & 1.38 & $0.038 \pm 0.028$ & 0.217 & 0.1263 & 0.0338 & $0.73 \pm 0.14$ \\
\hline \multirow[t]{2}{*}{$\zeta$-carotene } & Kushinotsu & 45 & 1.76 & $0.147 \pm 0.028$ & 0.215 & 0.1152 & 0.0342 & $0.70 \pm 0.10$ \\
\hline & Okitsu & 45 & 2.79 & $0.361 \pm 0.023$ & & 0.1052 & 0.0242 & $0.77 \pm 0.11$ \\
\hline$\beta$-carotene & Kuchinotsu & 46 & 0.83 & $-0.197 \pm 0.023$ & 0.125 & 0.1267 & 0.0250 & $0.80 \pm 0.10$ \\
\hline \multirow[t]{2}{*}{$\beta$-cryptoxanthin } & Kuchinotsu & 48 & 10.32 & $0.919 \pm 0.021$ & 0.131 & 0.1149 & 0.0212 & $0.82 \pm 0.07$ \\
\hline & Okitsu & 48 & 13.86 & $1.050 \pm 0.014$ & & 0.1034 & 0.0097 & $0.91 \pm 0.08$ \\
\hline \multirow[t]{2}{*}{ Zeaxanthin } & Kuchinotsu & 47 & 0.65 & $-0.239 \pm 0.019$ & 0.035 & 0.0554 & 0.0169 & $0.70 \pm 0.11$ \\
\hline & Okitsu & 47 & 0.71 & $-0.204 \pm 0.021$ & & 0.0583 & 0.0198 & $0.66 \pm 0.11$ \\
\hline \multirow[t]{2}{*}{ Violaxanthin } & Kuchinotsu & 48 & 6.79 & $0.726 \pm 0.013$ & 0.103 & 0.0926 & 0.0081 & $0.91 \pm 0.08$ \\
\hline & Okitsu & 48 & 9.28 & $0.829 \pm 0.021$ & & 0.1052 & 0.0207 & $0.80 \pm 0.07$ \\
\hline
\end{tabular}

${ }^{\mathrm{z}}$ Number of cultivars and selections applied for regression analysis, in which a carotenoid was detected at only one location were eliminated from regression analysis.

${ }^{y_{S E}}$ of the measurement data (phenotypic value) based on five fruit on one tree for 1 year in a location, which was the square root value of the environmental variance estimates $\left(\sigma_{e}^{2}\right)$ divided by the number of samples.

${ }^{\mathrm{x}}$ Contents analyzed as log-transformed values.

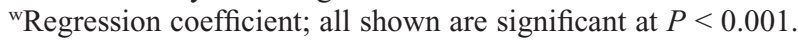

$\mathrm{FW}=$ fresh weight. 


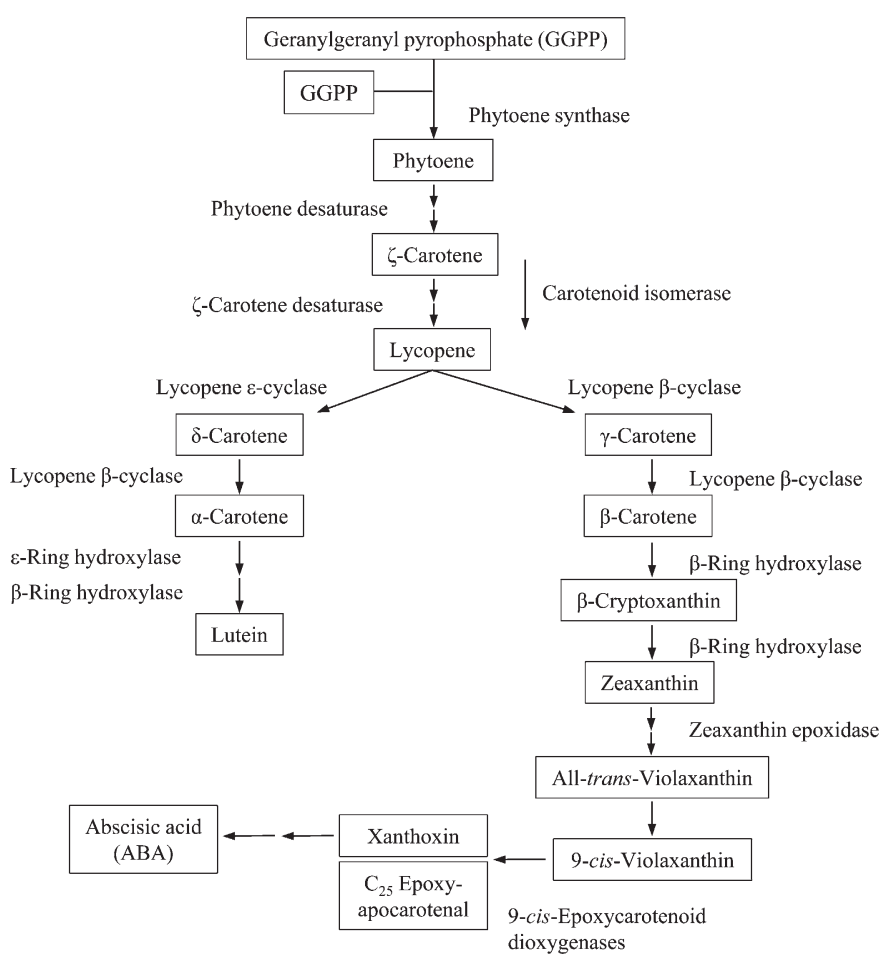

Fig. 2. Pathways of carotenoid and abscisic acid biosynthesis from 9-cisviolaxanthin in plants.

$0.35 \mu \mathrm{g} \cdot \mathrm{g}^{-1} \mathrm{ZCA}, 0.05 \mu \mathrm{g} \cdot \mathrm{g}^{-1} \mathrm{ACA}, 0.77 \mu \mathrm{g} \cdot \mathrm{g}^{-1} \mathrm{LUT}, 10.51 \mu \mathrm{g} \cdot \mathrm{g}^{-1}$ BCR, $3.01 \mu \mathrm{g} \cdot \mathrm{g}^{-1}$ BCA, $1.17 \mu \mathrm{g} \cdot \mathrm{g}^{-1}$ ZEA, $10.02 \mu \mathrm{g} \cdot \mathrm{g}^{-1}$ VIO, and $31.26 \mu \mathrm{g} \cdot \mathrm{g}^{-1}$ CAR (H. Matsumoto, personal communication; Matsumoto et al., 2007). Those in our population were comparable to that reported by Matsumoto et al. (2007). Thus, the mean carotenoid contents in the NIFTS parental population did not change substantially from those in the initial mandarin population, although other fruit qualities have improved significantly (Matsumoto, 2001; Matsumoto et al., 2003; Nishiura et al., 1983; Yoshida et al., 2005a, 2005b). This is highly advantageous for the present breeding target of combining high fruit qualities and high carotenoid content.

The environmental variances estimated here can be used in the breeding selection aiming at selecting seedlings having high genotypic values for carotenoid content from a hybrid seedling population. A critical value for phenotypic selection can be calculated from the estimate of environmental variance.

If hybrid seedlings were grown and evaluated at Kuchinotsu in the same way as here (five fruit from one tree), the breeder can select all seedlings showing values exceeding a critical value. In the case of $\mathrm{BCR}$, the log-transformed value of the measurement value (phenotypic value) of a genotype of seedling is assumed to distribute normally with the mean of its genotypic value (log-transformed value) and the environmental variance $\left(\sigma_{e 1}^{2}=0.0212 ;\right.$ Table 2). If the breeder desires to select seedlings with a genotypic value for BCR of greater than 1.477 $\left(\log 30.00 \mu \mathrm{g} \cdot \mathrm{g}^{-1} \mathrm{FW}\right)$, the $95 \%$ lower one-sided confidence limit is calculated as $1.477-1.645 \times \sqrt{ } 0.0212=1.238(\log$ $\left.17.30 \mu \mathrm{g} \cdot \mathrm{g}^{-1} \mathrm{FW}\right)$. Therefore, the breeder should discard all seedlings with a phenotypic value of less than $17.30 \mu \mathrm{g} \cdot \mathrm{g}^{-1} \mathrm{BCR}$.

Our results showed distinguishable cultivar differences of carotenoid contents and compositions among 48 genotypes (Fig. 1). Previous reports suggested that the accumulation of each carotenoid is highly regulated by the balance between the expression of upstream synthesis genes (encoding phytoene synthase, phytoene desaturase, $\zeta$-carotene desaturase, and lycopene $\beta$-cyclase) and downstream synthesis genes (encoding $\beta$-ring hydroxylase, zeaxanthin epoxidase, and 9-cis-epoxycarotenoid dioxygenases) and by the substrate specificity of $\beta$-ring hydroxylase (Kato et al., 2004, 2006, 2007; Rodrigo et al., 2004). The simultaneous high expression of upstream synthesis genes would lead to massive accumulation of $\beta, \beta$-xanthophylls (BCA, BCR, ZEA, VIO). In addition, if the expression of the genes for $\beta$-ring hydroxylase and zeaxanthin epoxidase is low, BCR would be accumulated, but not BCA, because of the high substrate specificity of $\beta$-ring hydroxylase for BCA (Kato et al., 2004). If the expression of 9-cisepoxycarotenoid dioxygenase genes was low, VIO would be accumulated (Kato et al., 2006). However, previous reports also suggest that the accumulation of CAR needs high expression of genes for both phytoene synthase and the methylerythritol 4-phosphate (MEP) pathway, which precedes the synthesis of geranylgeranyl pyrophosphate (Kato et al., 2007; Lois et al., 2000). These results suggest that the factors controlling carotenoid biosynthesis differ depending on genotype. 'King' had very high CAR and VIO but moderate BCR. 'Seinannohikari' had very high CAR and BCR but moderate VIO. These results lead us to the hypothesis that both 'King' and 'Seinannohikari' have very high expression of the upstream genes in the carotenoid biosynthesis pathway and of the genes of the MEP pathway, that 'King' has low expression of the genes for 9-cis-epoxycarotenoid dioxygenases, and that 'Seinannohikari' has low expression of the genes for $\beta$-ring hydroxylase and zeaxanthin epoxidase. Therefore, developing new cultivars with very high BCR content can be achieved by focusing on very high expression of the upstream genes in the carotenoid biosynthesis pathway and of the genes in the MEP pathway and on very low expression of the genes for $\beta$-ring hydroxylase and zeaxanthin epoxidase. Under this hypothesis, if a genotype with a very high CAR content but a low BCR content such as 'King', it is crossed with a genotype with low expression of the genes for $\beta$-ring hydroxylase and zeaxanthin epoxidase such as Satsuma mandarin (Kato et al., 2004), it might be possible to develop a cultivar with very high BCR content. However, the inheritances of CAR and individual carotenoids must first be elucidated.

We have shown that it is possible to select hybrid seedlings for BCR content by using an estimate of environmental variance, but the analysis of many seedlings is expensive. A cheaper method will need to be developed for efficient practical breeding. For example, selection using another trait that can be evaluated easily and that is highly correlated with carotenoid content or by DNA markers linked with carotenoid content may be effective.

\section{Literature Cited}

Davies, B.H. 1976. Carotenoids, p. 38-165. In: Goodwin, T.W. (ed.). Chemistry and biochemistry of plant pigments. Vol. 2. Academic Press, London, UK.

Dhuique-Mayer, C., C. Caris-Veyrat, P. Ollitrault, F. Curk, and M.J. Amiot. 2005. Varietal and interspecific influence on micronutrient contents in citrus from the Mediterranean area. J. Agr. Food Chem. 53:2140-2145.

Dhuique-Mayer, C., A.L. Fanciullino, C. Dubois, and P. Ollitrault. 2009. Effect of genotype and environment on citrus juice carotenoid content. J. Agr. Food Chem. 57:9160-9168. 
Fanciullino, A.L., C. Dhuique-Mayer, F. Luro, J. Casanova, R. Morillon, and P. Ollitrault. 2006. Carotenoid diversity in cultivated citrus is highly influenced by genetic factors. J. Agr. Food Chem. 54:43974406.

Farnham, M.W. and D.A. Kopsell. 2009. Importance of genotype on carotenoid and chlorophyll levels in broccoli heads. HortScience 44:1248-1253.

Goodner, K.L., R.L. Rouseff, and H.J. Hofsommer. 2001. Orange, mandarin, and hybrid classification using multivariate statistics based on carotenoid profiles. J. Agr. Food Chem. 49:1146-1150.

Goodwin, T.W. 1980. The biochemistry of the carotenoids. Chapman and Hall, London, UK.

Gross, J. 1987. Pigments in fruits. Academic Press, London, UK. Haynes, K.G., B.A. Clevidence, D. Rao, B.T. Vinyard, and J.M. White. 2010. Genotype $\times$ environment interactions for potato tuber carotenoid content. J. Amer. Soc. Hort. Sci. 135:250-258.

Hodgson, R.W. 1967. Horticultural varieties of citrus, p. 431-592. In: Reuther, W., H.J. Webber, and L.D. Batchelor (eds.). The citrus industry. Vol. 1. (revised ed.). Univ. of California, Berkeley, CA.

Ikoma, Y., A. Komatsu, M. Kita, K. Ogawa, M. Omura, M. Yano, and T. Moriguchi. 2001. Expression of a phytoene synthase gene and characteristic carotenoid accumulation during citrus fruit development. Physiol. Plant. 111:232-238.

Kato, M., Y. Ikoma, H. Matsumoto, M. Sugiura, H. Hyodo, and M. Yano. 2004. Accumulation of carotenoids and expression of carotenoid biosynthetic genes during maturation in citrus fruit. Plant Physiol. 134:824-837.

Kato, M., H. Matsumoto, Y. Ikoma, T. Kuniga, N. Nakajima, T. Yoshida, and M. Yano. 2007. Accumulation of carotenoids and expression of carotenoid biosynthetic genes and carotenoid cleavage dioxygenase genes during fruit maturation in the juice sacs of 'Tamami', 'Kiyomi' tangor, and 'Wilking' mandarin. J. Jpn. Soc. Hort. Sci. 76:103-111.

Kato, M., H. Matsumoto, Y. Ikoma, H. Okuda, and M. Yano. 2006. The role of carotenoid cleavage dioxygenases in the regulation of carotenoid profiles during maturation in citrus fruit. J. Expt. Bot. 57:2153-2164.

Lois, L.M., M. Rodriguez-Concepcion, F. Gallego, N. Campos, and A. Boronat. 2000. Carotenoid biosynthesis during tomato fruit development: Regulatory role of 1-deoxy-D-xylulose 5-phosphate synthase. Plant J. 22:503-513.

Matsumoto, H., Y. Ikoma, M. Kato, T. Kuniga, N. Nakajima, and T. Yoshida. 2007. Quantification of carotenoids in citrus fruit by LCMS and comparison of patterns of seasonal changes for carotenoids among citrus varieties. J. Agr. Food Chem. 55:2356-2368.

Matsumoto, R. 2001. 'Shiranuhi', a late-maturing citrus cultivar. Bul. Fruit Tree Res. Sta. 35:115-120 [in Japanese].

Matsumoto, R., M. Yamamoto, T. Kuniga, T. Yoshioka, N. Mitani, N. Okudai, Y. Yamada, K. Asada, H. Ikemiya, K. Yoshinaga, S. Uchihara, I. Oiyama, and H. Murata. 2003. New citrus cultivar 'Setoka'. Bul. Natl. Inst. Fruit Tree Sci. 2:25-31 [in Japanese].

Nicolosi, E., Z.N. Deng, A. Gentile, S. La Malfa, G. Comtimella, and E. Tribulato. 2000. Citrus phylogeny and genetic origin of important species as investigated by molecular markers. Theor. Appl. Genet. 100:1155-1166.

Nishino, H., H. Tokuda, M. Murakoshi, Y. Satomi, M. Masuda, M. Onozuka, S. Yamaguchi, J. Takayasu, J. Tsuruta, M. Okuda, F. Khachik, T. Narisawa, N. Takasuka, and M. Yano. 2000. Cancer prevention by natural carotenoids. Biofactors 13:89-94.

Nishiura, M., T. Shichijo, I. Ueno, M. Iwamasa, T. Kihara, Y. Yamada, T. Yoshida, and T. Iwasaki. 1983. New citrus cultivar 'Kiyomi' tangor. Bul. Fruit Tree Res. Sta. Ser. B Okitsu 10:1-9 [in Japanese].
Nyquist, W.E. 1991. Estimation of heritability and prediction of selection response in plant populations. Crit. Rev. Plant Sci. 10:235-322.

Olson, J.A. 1989. Provitamin-A function of carotenoids-The conversion of beta-carotene into vitamin-A. J. Nutr. 119:105-108.

Rodrigo, M.J., J.F. Marcos, and L. Zacarias. 2004. Biochemical and molecular analysis of carotenoid biosynthesis in flavedo of orange (Citrus sinensis L.) during fruit development and maturation. J. Agr. Food Chem. 52:6724-6731.

Rouseff, R., L. Raley, and H.J. Hofsommer. 1996. Application of diode array detection with a C-30 reversed phase column for the separation and identification of saponified orange juice carotenoids. J. Agr. Food Chem. 44:2176-2181.

Sugiura, M., M. Kato, H. Matsumoto, A. Nagao, and M. Yano. 2002a. Serum concentration of beta-cryptoxanthin in Japan reflects the frequency of Satsuma mandarin (Citrus unshiu Marc.) consumption. J. Health Sci. 48:350-353.

Sugiura, M., H. Matsumoto, and M. Yano. 2002b. Cross-sectional analysis of Satsuma mandarin (Citrus unshiu Marc.) consumption and health status based on a self-administered questionnaires. J. Health Sci. 48:366-369.

Sugiura, M., H. Matsumoto, M. Kato, Y. Ikoma, M. Yano, and A. Nagao. 2004. Seasonal changes in the relationship between serum concentration of beta-cryptoxanthin and serum lipid levels. J. Nutr. Sci. Vitaminol. (Tokyo) 50:410-415.

Sugiura, M., M. Nakamura, Y. Ikoma, M. Yano, K. Ogawa, H. Matsumoto, M. Kato, M. Ohshima, and A. Nagao. 2006. The homeostasis model assessment-insulin resistance index is inversely associated with serum carotenoids in non-diabetic subjects. J. Epidemiol. 16:71-78.

Sugiura, M., M. Nakamura, K. Ogawa, Y. Ikoma, F. Ando, H. Shimokata, and M. Yano. 2011. Dietary patterns of antioxidant vitamin and carotenoid intake associated with bone mineral density: Findings from post-menopausal Japanese female subjects. Osteoporos. Intl. 22:143-152.

Sugiura, M., M. Nakamura, K. Ogawa, Y. Ikoma, F. Ando, and M. Yano. 2008. Bone mineral density in post-menopausal female subjects is associated with serum antioxidant carotenoids. Osteoporos. Intl. 19:211-219.

Tanaka, T. 1954. Species problem in citrus (revisio auranti acearum IX). Jpn. Soc. Promotion Sci., Tokyo, Japan.

Tanaka, T., H. Kohno, M. Murakami, R. Shimada, S. Kagami, T. Sumida, Y. Azuma, and H. Ogawa. 2000. Suppression of azoxymethaneinduced colon carcinogenesis in male F344 rats by mandarin juices rich in beta-cryptoxanthin and hesperidin. Intl. J. Cancer 88:146-150.

Yamada, M., H. Yamane, and Y. Ukai. 1994. Efficiency of use of control genotypes for reducing yearly fluctuations of quantitative fruit characters in japanese persimmon breeding. Bul. Fruit Tree Res. Sta. 26:29-37.

Yamada, M., H. Yamane, K. Yoshinaga, and Y. Ukai. 1993. Optimal spatial and temporal measurement repetition for selection in japanese persimmon breeding. HortScience 28:838-841.

Yamaguchi, M. 2008. $\beta$-Cryptoxanthin and bone metabolism: The preventive role in osteoporosis. J. Health Sci. 54:356-369.

Yoshida, T., H. Nesumi, T. Yoshioka, Y. Ito, M. Yano, M. Nakano, I. Ueno, Y. Yamada, K. Ogawa, S. Murase, F. Takishita, T. Hidaka, and S. Kawai. 2005a. 'Kankitsu Chukanbohon Nou 6 Gou' ('Citrus Parental Line Norin No. 6') is useful for breeding seedless and functional component-rich cultivars. Bul. Natl. Inst. Fruit Tree Sci. 4:53-59 [in Japanese].

Yoshida, T., H. Nesumi, T. Yoshioka, M. Nakano, Y. Ito, S. Murase, and F. Takishita. 2005b. New citrus cultivar 'Harehime'. Bul. Natl. Inst. Fruit Tree Sci. 4:37-45 [in Japanese]. 